\title{
Multi-User And Real-Time Flexible Remote Laboratory Architecture for Collaborative and Cooperative Pedagogical Scenarios
}

\author{
http://dx.doi.org/10.3991/ijoe.v12i04.5097

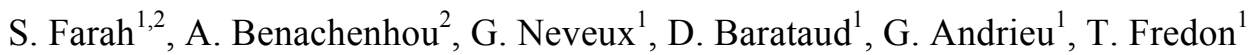 \\ ${ }^{1}$ University of Limoges, Limoges, France \\ ${ }^{2}$ University of Mostaganem, Algeria
}

\begin{abstract}
An advanced multi-user and realtime INTernational-REmote-LABoratory (INT-RE-LAB) architecture is presented in this paper. The INT-RE-LAB is developed and localized in four different host universities. The software part is based on the use of a free license server Node.js written in JavaScript. It offers lightweight $\mathbf{H t m l} / \mathbf{J a v a S c r i p t}$ clients. The integration of socket.io module enables a realtime operation mode of this Client/Server communication. Associated with hardware architecture, collaborative remote handling of resources is enabling in the same way as a chat communication used in Internet. Each remote action performed by one user is instantaneously visible in other users'web interfaces. The hardware part includes a minicomputer that executes node.js server and hosts Mysql. Mini-computer "Pcduino" directly controls specifically developed relays circuits. These circuits offer the required flexibility and reusability for current remote laboratories. Different redundant remote practical works integrate the INT-RE-LAB have been developed for the new EOLES "Electronics and Optic e-Learning for Embedded Systems" bachelor.
\end{abstract}

Index Terms - remote laboratory, real time, cooperative, collaborative, INTernational-REmote-LABoratory.

\section{INTRODUCTION}

After several years of development and progression, the new generations of remote laboratories tends to flexible and reusable architectures [1] [2] [3]. Point of view of teaching, the aim is to reproduce and ensure the learning offered in a face-to-face laboratory to a remote user. Several examples of remote laboratories have been developed in this background [4] [5]. Some of remote laboratories developed for a single application also remain relevant [6], it allows to provide specific and unique solutions such as remote control of equipment's designed to be handled in face-to-face labs [7]. An old version of the remote laboratory presented in this paper is based on the use of Ajax with the use of a computer as a web and databases server and an Arduino as Ethernet interface to the relay cards $(\mathrm{FHI})[8$.

\section{DESCRIPTION OF THE INTERNATIONAL REMOTE LABORATORY NETWORK ARCHITECTURE}

\section{A. General description}

The network architecture of the INT-RE-LAB is described in Fig. 1. It is composed of 4 identical and redundant REmote LABoratory (RE-LAB) based on 3 identical

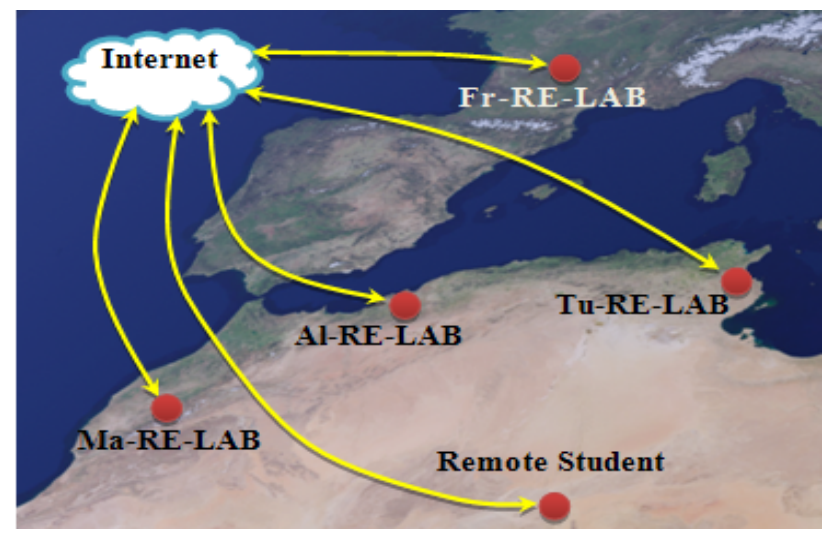

Figure 1. Network Architecture of the INT-RE-LAB

Local Area Networks (LAN) provided by each University (Al-RE-LAB: Mostaganem University-Algeria, Fr-RELAB: Limoges University-France, Ma-RE-LAB: University-Marrakach-Morocco, Tu-RE-LAB: KairouanUniversity-Tunis).

Remote students with a unique login and password provided by the Central Authentication Service (CAS) server can access indifferently the 4 remote LABs.

To complete understanding of their theoretical course materials, the INT-RE-LAB provides them different lab skills by controlling remote electronics and optics practical experiments. In such context, it is highly necessary to provide them the capability to work on different experiments based on an identical architecture.

\section{Description Of The Remote LAB ARChitecture}

\section{A. Software architecture based on node.js}

The software architecture of the remote laboratory is based on using node.js to implement the client-server system written in JavaScript. Communication between clients and server is provided by socket.io module offering real-time data exchange. The distant user access is provided using MySQL database managed by the server using MySQL Module installed on Node.js.

The client-server architecture and databases are hosted on a low cost mini-computer (PCDuino) equipped with the Linux operating system on a free distribution "Lubuntu". The client manipulates in its web page the SVG electronic circuit. Commands are sent in real time to the server and PCDuino digital outputs are set to high or low voltage as demonstrated in Fig. 2. 


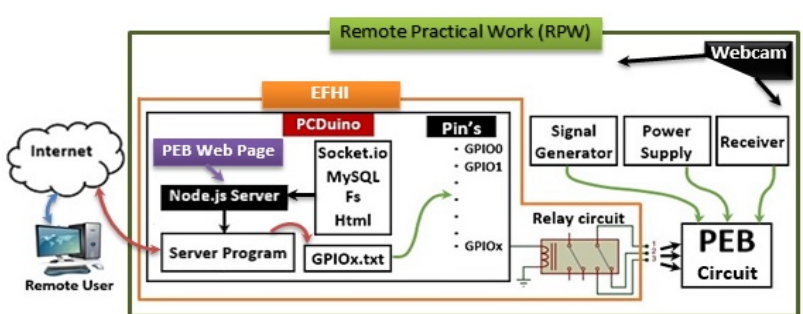

Figure 2. General software/hardware architecture of remote practical works

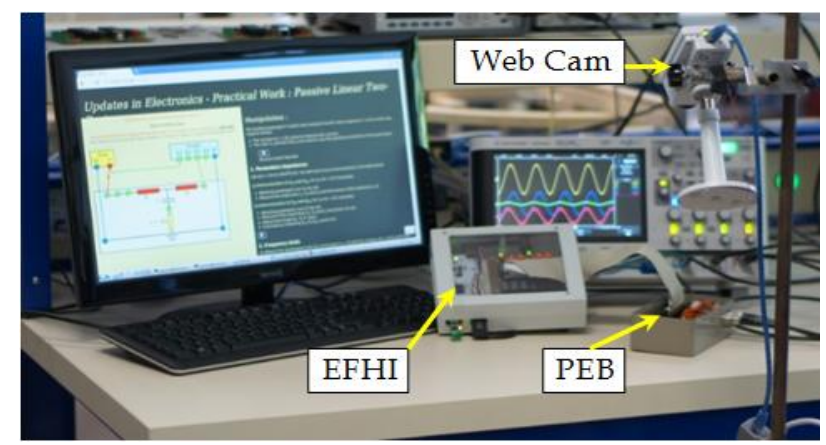

Figure 3. Picture of a Remote Practical Work (RPW) of the INT-RELAB

\section{B. Hardware architecture based on EFHI/PEB}

Hardware architecture of the remote laboratory is composed mainly of an EFHI (Flexible Ethernet Hardware Interface) and PEB (Practical Evaluation Board) provided for each practical work. The new version of the board EFHI consists of a PCDuino platform that controls a 13 relays card by its digital outputs (Pins) called GPIO. Fig. 3 illustrates the remote laboratory in real test.

\section{New EFHI/PEB structure}

The new version of the EFHI illustrated in Fig. 4 has been developed to meet the needs of remote laboratories implemented under the European Tempus program that prepares L3 Bachelor program L3 named EOLES "Optics and Electronics e-Learning for Embedded Systems". This bachelor has the particularity of fully remotely learned including practical work of different teaching units.

\section{Web Client InTERfaces Structure}

\section{A. Web interface structure}

HTML client's remote laboratory are provided by a server program written in JavaScript and running with node.js. Node.js is a free platform built in JavaScript language, easy to install and building fast scalable network applications. Node.js is lightweight and efficient, perfect for data-intensive real-time applications that run across distributed devices.

The web client can be loaded on each request from a remote user by specifying the IP address of server in PCDuino. The design of electronic circuits on the web pages is made in SVG "Scalable Vector Graphics". This language producing a lightweight and dynamic graphics through JavaScript functions associated with OnClick event.

\section{B. Remote manipulation of practical works}

After authentication, the remote user connects as a client to the server that runs on PCDuino. The practical work

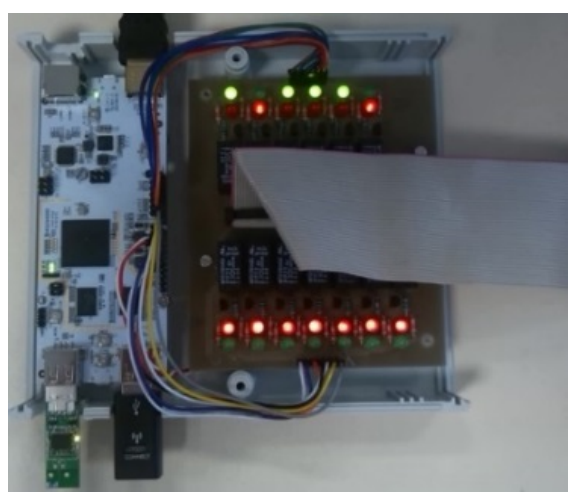

Figure 4. EFHI in real test with 4 relays used Picture of a Remote Practical Work (RPW) of the INT-RE-LAB

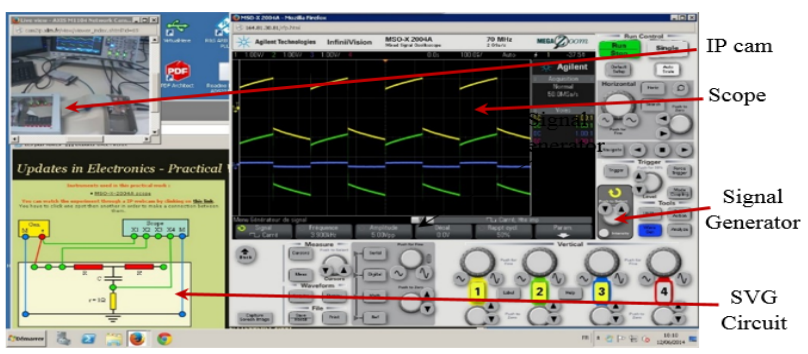

Figure 5. Student desktop in real manipulation of a remote practical work

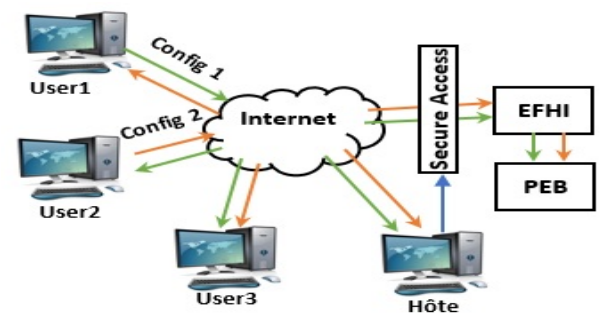

Figure 6. Chat aspect for collaborative remote lab manipulation

involves loading web interface designed for the current PEB (Client), the front faces of different instruments and captured image by IP cam focused on the remote laboratory for real-time projection of remote user manipulations. In Fig. 5 a screenshot of a real remote manipulation is illustrated.

\section{Operating OF THE REMOte LABORATORY}

\section{A. Chat aspect for collaborative remote lab manipulation}

The principle of Internet Chat is based on broadcasting the message sent by a user to all subscribers. This aspect is also included in remote learning platforms like Moodle or virtual classroom as Adobe Connect or BigBlueButton.

This principle has been applied in the software architecture of the remote laboratory presented in this paper. Handling of each user is transmitted and applied to the web user's interface simultaneously with applying to real remote practical work. This principle applies to all users as the classical internet Chat. See Fig. 6.

\section{B. Application in the EOLES bachelor Tempus program}

The platform of this remote laboratory was adopted by the Preparatory Committee for EOLES project. It will be made according to the practical work will be installed in 
member universities of the project and allow students to perform their practical work. Reproduced Flexibility, reusability and ease design of EFHI and practical works PEB justify the choice of this platform to be adopted for EOLES program.

\section{Vi. Pedagogical Scenari For Collaborative And COOPERATIVE REMOTE PRACTICAL WORK}

Thanks to the software and hardware flexibility of all RPW of the INT-RE-LAB, other pedagogical scenario can be implemented depending on the pedagogical objectives desired by the tutor/teacher.

\section{A. Scenario 1: Authority/Tutor demonstration}

In this case, the tutor entirely controls the RPW and applies the configuration on the PEB-circuit. Fig. 7 shows that students receives in real-time the RPW configuration changes made by the tutor. So they are observers and are not authorized to modify the circuit configuration. This scenario can be used by the tutor to demonstrate the operating mode of the RPW to all students. Collaborative work is reduced only to synchronous questions or discussions between tutor and students in the virtual class. They also have the front panel of instruments in their screens to allow them to follow the demonstration made by the tutor.

\section{B. Scenario 2: Unique student modification under host control}

Fig. 8 shows a second possible scenario. The tutor gives authorization to a unique student to control and configure the RPW at a time. When a student has permission to configure the PEB, the others become observers and configuration is shown in real-time in student's web interfaces. Student 1 applies configuration " 2 " (config2) to the PEB circuit and the other student and the tutor are observers. In this scenario, the tutor asked the student 1 to perform the RPW following his advices and also the other student's opinions and recommendation given in the associated virtual class. The tutor can change at any time the student's rights to involve another one in the conduct of the RPW.

\section{Scenario 3: Programmed successive access to $R P W$}

In this third scenario, each student has a time slot with granted PEB modification rights to apply the different configurations required in a text document to perform an individual RPW. The student can successively access to the RPW during scheduled "T" time slot: student 1 performs his individual work from to to t0+T. Student 2 does the same later, between $\mathrm{t} 1$ and $\mathrm{t} 1+\mathrm{T}$ with $(\mathrm{t} 1>\mathrm{t} 0+\mathrm{T})$ and so on for all students. Fig. 9 represents the pedagogical method of individual RPW realization. A collaborative and cooperative work is possible if two students have authorization to manipulate RPW in the same time slot.

\section{SURVEY RESULTS}

The L3-EOLES course, a fully online 3rd year Bachelor degree in Electronics and Optics for Embedded Systems, is the most prominent outcome of the EOLES project, a 3year European TEMPUS project involving 15 institutions, four from Europe and eleven from the North African countries of Algeria, Morocco, and Tunisia [9]. The courses have started in September 2014.

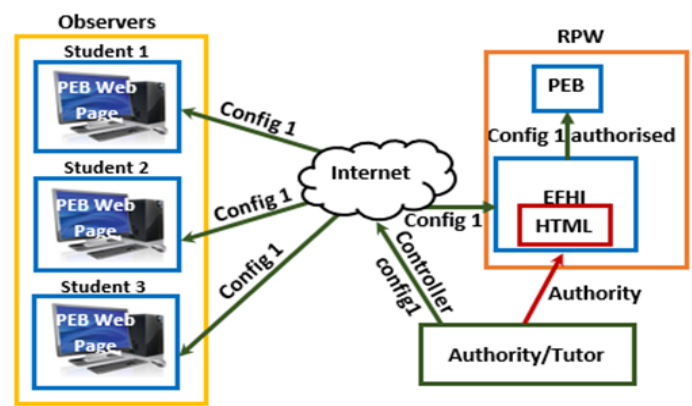

Figure 7. Demonstration session and authorization architecture for scenario 1

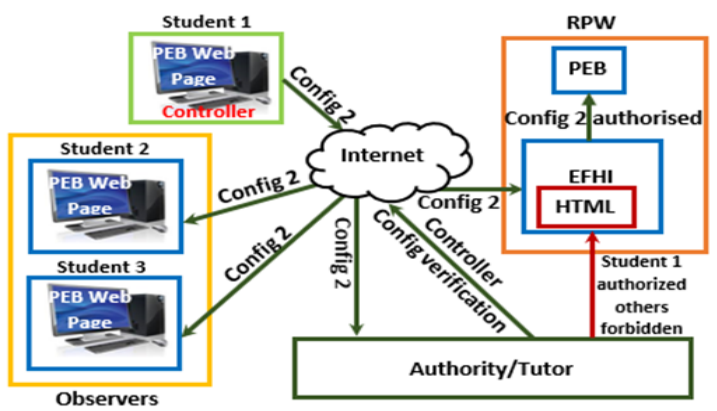

Figure 8. Demonstration session associated with remote class

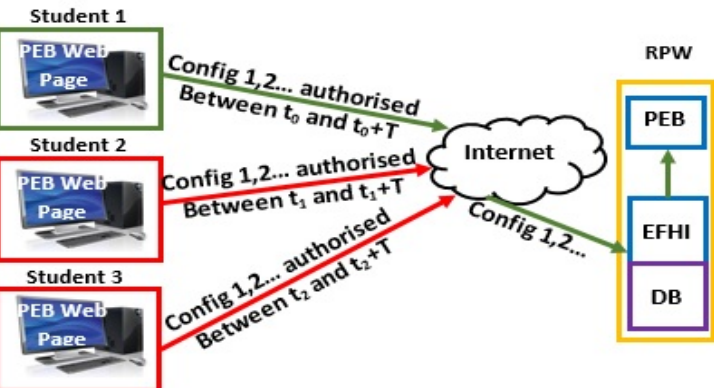

Figure 9. Authorization to one student access at a time slot

For this first edition, 22 undergraduate students are enrolled, 45 students are selected for the second 2015-2016 edition. Five main technical units of the bachelor program have been involved in RPW as shown in Table I: 20 RPW have been finally developed for this 1 st edition and 44 PEBs have been designed.

They were surveyed to access their perception and their opinion for all the TU. A specific question has been proposed to the student concerning the RPW.

The students have to give a racing to all RPW of each TU. The minimum score is (1) corresponding to "Strongly disagree". The maximum score is (5) corresponding to "Strongly agree". The Table II shows the number of students' responses for all TU with RPW. All students who have been assiduously trained have answered to this questionnaire. It can be observed that the mean value of students 'answers is always higher than 3. It means that, for these students, for which ones it was the first experience with RPW, the perception of the INT-RE-LAB was rather positive. This result encourages its further development enhancement. As a consequence, the program of the TU will be slightly modified in the next edition to develop specific courses to specifically learn operating working mode of the EFHI. 
TABLE I.

RPW IN THE FIRST EOLES EDITION

\begin{tabular}{|l|c|}
\hline \multicolumn{1}{|c|}{ TU } & Realized PW \\
\hline TU04 Analog electronics for embedded systems & 4 \\
\hline TU06 Wave and propagation for embedded systems & 3 \\
\hline TU07 Power electronics and embedded systems & 3 \\
\hline TU10 Signal processing & 4 \\
\hline TU11 Instrumentation & 4 \\
\hline
\end{tabular}

TABLE II.

RPW SURVEY RESULTS

\begin{tabular}{|c|c|c|}
\hline TU with PW & Number of student's responses & Mean value/5 \\
\hline TU04 & 18 & 3.66 \\
\hline TU06 & 19 & 3.66 \\
\hline TU07 & 17 & 3.14 \\
\hline TU10 & 18 & 3.84 \\
\hline TU11 & 18 & 3.52 \\
\hline
\end{tabular}

\section{CONCLUSION}

The architecture of a remote laboratory developed and presented for the preparation of EOLES "Electronic and Optic e-Learning for Embedded Systems" bachelor practical works that is launched in September 2014. It is a flexible architecture adaptable to several disciplines in the teaching of EOLES units.

The software architecture of the remote laboratory provides real-time communication using HTML/JS/SVG clients. By using the Chat principle, the server program provides a new technique for collaborative work to one or more remote users to manipulate in real time hardware resources of the remote laboratory.

The main originality of this architecture concerns the capability now given to teacher and student to work with different pedagogical methods implemented in various collaborative and cooperative operating modes in a multiuser context. The achieved flexible architecture also allows further exploring other new innovative pedagogical methods for collaborative work of group of students performing the same remote practical work at a time.

\section{ACKNOWLEDGMENT}

Authors would like to thank to all the technical and pedagogical teams working on this project for their support.

The work reported here was performed in the context of the European Tempus project and supported by the European Union under contract $n^{\circ}$ 530466-TEMPUS-1-20121-FR-TEMPUS-JPCR.

\section{REFERENCES}

[1] O. Salaheddin, "A Web-Based Remote Lab Platform with Reusability for Electronic Experiments in Engineering Education," iJOE - Volume 10, Issue 4, 2014.
[2] N. Sousa, G.R. Alves, and M.G. Gericota, "An Integrated Reusable Remote Laboratory to Complement Electronics Teaching," Learning Technologies, IEEE Transactions on ducation, Volume: 3 , Issue: 3, Page(s): $265-271,2010$.

[3] U. Hernandez-Jayo, J. Garcia-Zubia, "Low cost remote and reconfigurable analog electronics laboratory," Remote Engineering and Virtual Instrumentation (REV), 2014 11th International Conference, date of Conference Porto 26-28 Feb, Pages 457 - 460, 2014.

[4] A. Kalantzopoulos and E. Zigouris "Online Laboratory Sessions in System Design,” iJOE - Volume 10, Issue 4, 2014.

[5] S. Odeh, M. Anabtawi, A.Ayesh, "Applying reusabililty in remote labs ," Electrotechnical Conference (MELECON), 2012 16th IEEE Mediterranean, Learning Technologies, date of Conference 25-28 March 2012, Pages 265 - 271, 2010. http://dx.doi.org/10.1109/melcon.2012.6196392

[6] A. K.M. Azad, and P. Kaushik, "RoombaCreate ${ }^{\circledR}$ for Remote Laboratories," iJOE - Volume 10, Issue 4, 2014.

[7] A. Kalantzopoulos, and E. Zigouris, "Online Laboratory Sessions in System Design with DSPs using the R-DSP Lab," iJOE - Volume 10, Issue 4, 2014.

[8] S.Farah, A. Benachenhou, G.Neveux, D.Barataud, "Design of a flexible architecture for characterization of active and passive microwave devices (patch antenna, filters, couplers and amplifier stage) in a remote laboratory," Global Engineering Education Conference (EDUCON), 2013 IEEE, Pages 847 - 853, 2013. http://dx.doi.org/10.1109/EduCon.2013.6530205

[9] M.Gericota, A.Vaz Fidalgo, D.Barataud, G.Andrieu, R.De Craemer, M.Cristea, A.Benachenhou, M.Ankrim, K.Bouchlaghem, P.Ferreira, "EOLES course the first accredited on-line degree course in electronics and optics for embedded systems", Global Engineering Education Conference (EDUCON), EDUCON.2015, Pages: 403 - 410 http://dx.doi.org/10.1109/educon.2015.7096004

\section{AUTHORS}

S. Farah is with the the Electrical Engineering Department and LEOG laboratory of Mostaganem University and XLIM laboratory of Limoges University, 123 Av. A. THOMAS 87050 LIMOGES, France. His research interests include remote labs conception and radiofrequency instrumentation, (said.farah@etu.unilim.fr).

A. Benachenhou is with the Physical Department and LEOG laboratory of Mostaganem University, Algeria. His research interests include ELearning technologies and remote labs development (abdelhalim.benachenhou.aff @unilim.fr).

G. Neveux is with the Physical Department and XLIM laboratory of Limoges University. His research interests include remote manipulation and radiofrequency instrumentation, (guillaume.neveux@xlim.fr).

D. Barataud is with XLIM laboratory, University of Limoges, 123 Av. A. THOMAS 87050 LIMOGES, France (e-mail: denis.barataud@xlim.fr).

This work was supported by EOLES Tempus project and XLIM laboratory of Limoges University, France.

Submitted, 09 March 2015. Published as resubmitted by the authors on 09 April 2015. 